\title{
Association between the auditory profile and speech-language-hearing diagnosis in children and adolescents
}

\author{
Marina Garcia de Souza Borges ${ }^{1}$ \\ https://orcid.org/0000-0002-4973-0560
}

Nathália Stefanny Oliveira Gomes ${ }^{1}$

https://orcid.org/0000-0002-9766-0341

Adriane Mesquita de Medeiros ${ }^{1}$

https://orcid.org/0000-0002-2817-2555

Stela Maris Aguiar Lemos ${ }^{1}$

https://orcid.org/0000-0003-4104-5179

Universidade Federal de Minas Gerais UFMG, Departamento de Fonoaudiologia, Belo Horizonte, Minas Gerais, Brasil.

Research support source: Coordenação de Aperfeiçoamento de Pessoal de Nível Superior - Brazil (CAPES) - Funding Code 001.

Conflict of interests: Nonexistent

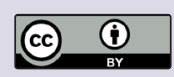

Received on: July 21, 2020

Accepted on: October 12, 2020

Corresponding address:

Marina Garcia de Souza Borges

Avenia Alfredo Balena, 190, sala 249

CEP: 30130-100 - Belo Horizonte,

Minas Gerais, Brasil

E-mail: ninaborgesvh@hotmail.com

\section{ABSTRACT}

Purpose: to verify the association between the auditory assessment result and the speech-language-hearing diagnosis in children and adolescents.

Methods: an observational, cross-sectional study based on the analysis of medical records of children and adolescents that received care at a speech-language-hearing assessment outpatient center between 2010 and 2014. Data on sociodemographic characteristics, speech-language-hearing diagnosis, auditory examination results, and Auditory Processing Simplified Assessment results were collected. Descriptive and association analyses were conducted with either the chi-squared or Fisher's exact test, considering the $5 \%$ statistical significance level.

Results: the sample comprised 122 participants, most of them males (67.2\%), mean age 8.78 years. A statistically significant association was verified between the audiometry result and the diagnostic hypothesis of change in written language $(p=0.011)$; between the results of both the sequential memory test for nonverbal sounds and sound localization and the diagnostic hypotheses of change in the cognitive aspects of language $(p=0.019$ and $p=0.033$, respectively) and of speech $(p=0.003$ and $p=$ 0.020 , respectively); and between the result of the sequential memory test for verbal sounds and the diagnostic hypothesis of change in speech $(p=0.005)$.

Conclusion: given the associations found, it is proposed that children and adolescents with changes in speech undergo the Auditory Processing Simplified Assessment to verify the possibility of changed aspects, favoring directed therapeutic interventions.

Keywords: Speech, Language and Hearing Sciences; Child; Adolescent; Hearing Tests; Diagnosis 


\section{INTRODUCTION}

The adequate functioning of both the peripheral and central auditory systems is essential to good language development ${ }^{1}$. The central auditory processing, an integral part of this system, is related to the efficiency and effectiveness with which the central nervous system processes the auditory information. There are in it the auditory mechanisms that are manifested in the skills of sound localization and lateralization, auditory discrimination, and the ones associated with temporal aspects of hearing ${ }^{2}$, such as temporal ordering, masking, and temporal integration and resolution ${ }^{3}$.

When the auditory processing is changed, difficulties may occur in comprehension, language and learning delays, and poor academic performance ${ }^{4}$. Due to the involvement of the temporal aspects in a great part of the communicative skills, the presence of other diagnoses related to speech-language-hearing (changes in speech, voice, phonological awareness, or cognitive aspects of language) may be associated with issues that refer to the simple temporal ordering of verbal and/or nonverbal sounds ${ }^{5}$.

Therefore, the existence of any type of communication disorder, such as speech and language delays or atypical development, requires individualized, early, and well-defined assessment of the speech-languagehearing aspects. This situation helps to guide the procedures related to the peripheral and central (when necessary) auditory ${ }^{6}$ assessment, as well as of the aspects of processing.

At the social level, the speech-language-hearing assessment process makes it possible to characterize the profile of the attendees of a given service, helping to manage and plan it, and to guide the actions related to preventing, promoting, and rehabilitating health, coherently with the needs of the population who attend the place ${ }^{7}$.

Hence, this study aimed to verify the association between the result of the auditory assessment and the speech-language-hearing diagnosis of children and adolescents that received care at a university outpatient center.

\section{METHODS}

This research was approved by the Research Ethics Committee of the Universidade Federal de Minas Gerais - UFMG, Minas Gerais, Brazil, under evaluation report number 1.174.646. It was also exempted from administering the informed consent form (ICF). This is an observational, descriptive, cross-sectional study, based on the retrospective analysis of the medical records of children and adolescents that received care from 2010 to 2014.

The study was set at an outpatient center that is part of the public health network of the state of Minas Gerais, Brazil. At the outpatient center, speechlanguage-hearing undergraduate students, supervised by a professor, assessed the patients referred by other specialties with complaints or signs of speech-language-hearing changes. At the beginning of the assessment process, structured anamnesis is performed around the following main themes: sociodemographic data (age, sex, both the patient's and parents' schooling level, income, place of residence, and so forth), previous history of speech-languagehearing complaint, neuropsychomotor development, and clinical/assistance trajectory. Then, protocols validated in the literature in the fields of oral and written language, fluency, orofacial motor functions, and voice are administered. They are selected based on the patient's clinical characteristics of age and schooling level, enabling a speech-language-hearing diagnosis with a generalized perspective. Also, diagnostic hypotheses in different fields may occur in the same patient. Afterward, the procedure for each case is defined: When and in what areas to begin the speech-language-hearing therapy, whether it is necessary to refer to other professionals, etc. At the end of the process, anamnesis and assessment reports are prepared, of which a copy is filed in the medical records. Such were the reports used as the data source for this study.

The inclusion criteria used to compose the sample encompassed having received care in the period from 2010 to 2014; being five years to 16 years and 11 months old by the time the speech-language-hearing assessment began; having an auditory examination, including audiometry and acoustic immittance, attached to the medical record; having the results of the Auditory Processing Simplified Assessment (ASPA, its Portuguese acronym $)^{8}$ described in the assessment report. The exclusion criteria were incomplete or inconclusive medical records or reports.

Anamnesis and assessment data were collected regarding the patients' characterization (age, sex, schooling level, and speech-language-hearing diagnosis), besides the auditory assessment data (results of the pure-tone threshold audiometry, speech audiometry, acoustic immittance, and ASPA ${ }^{8}$ ). 
Descriptive analysis was conducted with the frequency distribution of the categorical variables, as well as the analysis of measures of central tendency and dispersion of the continuous variables. To this end, the data were first entered into an Excel databank and then evaluated. An analysis was also conducted to verify the association between the explanatory variables - age, sex, patient's schooling level, and speech-languagehearing diagnosis - and the response variables resulting from the audiometric assessment, acoustic immittance, Sequential Memory Test for Nonverbal Sounds (SMNV), Sequential Memory Test for Verbal Sounds (SMV), and sound localization. Either the Pearson chi-squared test was used, or Fisher's exact test, when this was more adequate. The $5 \%$ statistical significance level was used. The data were entered, processed, and analyzed with the Statistical Package for the Social Sciences (IBM SPSS - version 23).

\section{RESULTS}

The sample comprised 122 children and adolescents, most of them (67.2\%) males, mean age 8.78 years $(S D=2.98)$. The two predominant age groups were from five to seven (42.6\%) and eight to 12 years old (42.6\%). Regarding the schooling level, the sample ranged from kindergarten to high school - most of them were enrolled in elementary school (81.1\%) (Table 1).

Table 1. General characterization of five- to 16-year-old patients

\begin{tabular}{llll}
\hline Variables & & N & $\%$ \\
\hline \multirow{2}{*}{ Age group (years) } & 5 to 7 & 52 & 42.6 \\
& 8 to 12 & 52 & 42.6 \\
\hline \multirow{2}{*}{ Sex } & 13 to 16 & 18 & 14.8 \\
\hline \multirow{3}{*}{ Schooling $\left(n=121^{*}\right)$} & Females & 40 & 32.8 \\
& Males & 82 & 67.2 \\
\hline & Kindergarten & 19 & 15.7 \\
& Elementary school & 99 & 81.8 \\
& Unfinished high school & 2 & 1.7 \\
\hline
\end{tabular}

Captions: $\mathrm{N}=$ Absolute frequency; $\%=$ Relative frequency; ${ }^{*}$ one participant did not inform his/her schooling level

The analysis of the main diagnostic hypotheses defined after finishing the assessment indicated that the most frequent speech-language-hearing changes were in written language $(62.3 \%)$, oral language $(59.3 \%)$, and orofacial motor functions (56.6\%). The only change not verified in the sample of the study was that of swallowing (0\%). Concerning hearing, $3.3 \%$ of the total sample were diagnosed with auditory changes, while $23.0 \%$ were diagnosed with a change in the auditory processing (Table 2). 
Table 2. Description of the diagnoses found in five- to 16-year-old patients assessed at a university outpatient center $(\mathrm{N}=122)$

\begin{tabular}{|c|c|c|c|}
\hline \multicolumn{2}{|c|}{ Changed areas regarding the diagnostic hypotheses } & \multirow{2}{*}{$\frac{\mathbf{N}}{73}$} & \multirow{2}{*}{$\begin{array}{r}\% \\
59.8\end{array}$} \\
\hline & Yes & & \\
\hline Oral Language & No & 49 & 40.2 \\
\hline \multirow{2}{*}{ Written Language } & Yes & 76 & 62.3 \\
\hline & No & 46 & 37.7 \\
\hline \multirow{2}{*}{ Cognitive Aspects of Language } & Yes & 61 & 50.0 \\
\hline & No & 61 & 50.0 \\
\hline \multirow{2}{*}{ Speech } & Yes & 47 & 38.5 \\
\hline & No & 75 & 61.5 \\
\hline \multirow{2}{*}{ Fluency } & Yes & 9 & 7.4 \\
\hline & No & 113 & 92.6 \\
\hline \multirow{2}{*}{ Orofacial Motor Functions } & Yes & 69 & 56.6 \\
\hline & No & 53 & 43.4 \\
\hline \multirow{2}{*}{ Swallowing } & No & 122 & 100.0 \\
\hline & Yes & 0 & 0.0 \\
\hline \multirow{2}{*}{ Voice } & Yes & 51 & 41.8 \\
\hline & No & 71 & 58.2 \\
\hline \multirow{2}{*}{ Hearing } & Yes & 4 & 3.3 \\
\hline & No & 118 & 96.7 \\
\hline \multirow{2}{*}{ Perceptual Processes* } & Yes & 58 & 47.5 \\
\hline & No & 64 & 52.5 \\
\hline \multirow{2}{*}{ Auditory Processing } & Yes & 28 & 23.0 \\
\hline & No & 94 & 77.0 \\
\hline Total & & 122 & 100.0 \\
\hline
\end{tabular}

* Changes in auditory memory, visual memory, and attention;

Captions: $\mathrm{N}=$ Absolute frequency; $\%=$ Relative frequency

A greater prevalence of normal hearing results was observed regarding the type $(94.2 \%$ for the right ear, and $93.4 \%$ for the left ear) and degree (95.0\% for the right ear, and $93.4 \%$ for the left ear). The conductive hearing loss was the most frequent type (3.3\%), and the type $\mathrm{C}$ curve the most prevalent, bilaterally $(8.1 \%$ for the right, and $4.5 \%$ for the left) (Table 3). The speech audiometry was performed in 120 patients (98.4\%). Of these, only 14 (11.3\%) did not take the speech recognition percentage index (SRPI), four (3.3\%) did not take the speech recognition threshold (SRT), and two (1.6\%) patients took the speech detection threshold (SDT).
Altogether, 112 patients (91.8\%) underwent acoustic immittance. Of these, $81.2 \%$ had an adequate result, with a predominance of type A curve for both ears $(91.0 \%$ for the right, and $93.7 \%$ for the left), and presence of contralateral acoustic reflex (56.5\%) (Table 3).

ASPA was present in 118 medical records (96.7\%). The analysis of the auditory skills revealed that $25.9 \%$ of the patients had changes in the SMNV, while $28.2 \%$ had changes in the SMV. The sound localization test was changed in $17.0 \%$ of the patients (Table 4), and the cochlear-palpebral reflex (CPR) was present in $93.4 \%$ of the sample. 
Table 3. Characterization of the results of the pure-tone audiometry, acoustic immittance, and acoustic reflex of five- to 16-year-old patients assessed at a university outpatient center $(\mathrm{N}=122)$

\begin{tabular}{|c|c|c|c|}
\hline Audiological assessment results & & $\mathbf{N}$ & $\%$ \\
\hline \multirow{3}{*}{ Type of hearing loss (right ear)* } & Normal & 114 & 94.2 \\
\hline & Sensorineural & 3 & 2.5 \\
\hline & Conductive & 4 & 3.3 \\
\hline \multirow{4}{*}{ Degree of hearing loss (right ear)* } & Normal & 114 & 95.0 \\
\hline & Mild & 4 & 3.3 \\
\hline & Discrete & 1 & 0.8 \\
\hline & Not informed & 1 & 0.8 \\
\hline \multirow{4}{*}{ Type of hearing loss (left ear) } & Normal & 114 & 93.4 \\
\hline & Sensorineural & 3 & 2.5 \\
\hline & Conductive & 4 & 3.3 \\
\hline & Not informed & 1 & 0.8 \\
\hline \multirow{5}{*}{ Degree of hearing loss (left ear)* } & Normal & 114 & 93.4 \\
\hline & Mild & 5 & 4.1 \\
\hline & Moderate & 1 & 0.8 \\
\hline & Discrete & 1 & 0.8 \\
\hline & Not informed & 1 & 0.8 \\
\hline \multirow{3}{*}{ Tympanometric curve (right ear) } & Type A & 101 & 91.0 \\
\hline & Type B & 1 & 0.9 \\
\hline & Type C & 9 & 8.1 \\
\hline \multirow{3}{*}{ Tympanometric curve (left ear)* } & Type A & 104 & 93.7 \\
\hline & Type B & 2 & 1.8 \\
\hline & Type C & 5 & 4.5 \\
\hline \multirow{2}{*}{ Acoustic immittance result* } & Changed & 21 & 18.7 \\
\hline & Adequate & 91 & 81.2 \\
\hline \multirow{3}{*}{ Contralateral acoustic reflex } & Absent & 29 & 23.8 \\
\hline & Present & 69 & 56.5 \\
\hline & Not performed & 24 & 19.7 \\
\hline
\end{tabular}

*Total number of patients differs as not all of them performed all the tests

Captions: Absent contralateral acoustic reflex = at least one frequency of the contralateral reflex was absent; Present contralateral acoustic reflex = All the frequencies with the presence of acoustic reflex; $\mathrm{N}=$ Absolute frequency; \%= Relative frequency

Table 4. Results of the Auditory Processing Simplified Assessment of five- to 16-year-old patients assessed at a university outpatient center

\begin{tabular}{lccc}
\hline Results & & $\mathbf{N}$ & $\%$ \\
\hline \multirow{3}{*}{ SMNV* $^{*}$} & Changed & 30 & 25.9 \\
& Adequate & 86 & 74.1 \\
& Total & 116 & 100.0 \\
\hline \multirow{2}{*}{ SMV* $^{*}$} & Changed & 33 & 28.2 \\
& Adequate & 84 & 71.8 \\
\hline \multirow{2}{*}{ Sound Localization* } & Total & 117 & 100.0 \\
& Changed & 20 & 17.0 \\
& Adequate & 98 & 83.0 \\
\hline
\end{tabular}

* Total number of patients differs as not all of them performed all the tests Captions: SMNV= Sequential memory test for nonverbal sounds; SMV= Sequential memory test for verbal sounds; $\mathrm{N}=$ Absolute frequency; $\%=$ Relative frequency 
A statistically significant association was verified between peripheral hearing loss and the diagnosis of written language change $(p=0.011)$. The result of the acoustic immittance did not present any association with the explanatory variables of the study. The result of the SMNV, in its turn, had a statistically significant association with the diagnostic hypotheses of change in the cognitive aspects of language $(p=0.019)$ and speech $(p=0.003)$. The result of the SMV had an association with the diagnostic hypothesis of change in speech $(p=0.005)$. As for sound localization, there was a statistically significant association with the diagnostic hypotheses of changes in speech $(p=0.020)$ and in cognitive aspects of language $(p=0.033)$ (Table 5).

Table 5. Association between the auditory assessment results and the sociodemographic factors and speech-language-hearing diagnoses of five- to 16-year-old patients assessed at a university outpatient center

\begin{tabular}{|c|c|c|c|c|c|c|c|c|c|c|c|c|c|c|c|c|}
\hline \multirow[t]{2}{*}{ Variables } & & \multicolumn{2}{|c|}{ HEARING LOSS } & \multirow{2}{*}{ p-value } & \multirow{2}{*}{\multicolumn{2}{|c|}{$\begin{array}{c}\text { ACOUSTIC } \\
\text { IMMITTANCE } \\
\text { Changed Adequate }\end{array}$}} & \multirow{2}{*}{$p$-value } & \multicolumn{2}{|c|}{ SMNV } & \multirow{3}{*}{ p-value } & \multicolumn{2}{|c|}{ SMV } & \multirow[t]{2}{*}{ p-value } & \multirow{2}{*}{\multicolumn{2}{|c|}{$\frac{\text { LOCALIZATION }}{\text { Changed Adequate }}$}} & \multirow[t]{2}{*}{ p-value } \\
\hline & & Chang & Adequate & & & & & Changed & Adequate & & Chang & dequate & & & & \\
\hline \multirow{3}{*}{$\begin{array}{l}\text { Age group } \\
\text { (years) }\end{array}$} & 5 to 7 & 5 & 46 & \multirow{3}{*}{$0.230^{(1)}$} & 7 & 43 & \multirow{3}{*}{$0.250^{(1)}$} & 17 & 31 & & 16 & 33 & \multirow{3}{*}{$0.489^{(1)}$} & 10 & 40 & \multirow{3}{*}{$0.700^{(1)}$} \\
\hline & 8 to 12 & 1 & 51 & & 12 & 34 & & 11 & 40 & \multirow[t]{2}{*}{$0.103^{(1)}$} & 14 & 37 & & 7 & 44 & \\
\hline & 13 to 16 & 1 & 17 & & 2 & 14 & & 2 & 15 & & 3 & 14 & & 3 & 14 & \\
\hline \multirow{2}{*}{ Sex } & Females & 2 & 38 & \multirow{2}{*}{$0.577^{(2)}$} & 4 & 30 & \multirow{2}{*}{$0.162^{(2)}$} & 11 & 27 & \multirow{2}{*}{$0.376^{(1)}$} & 13 & 25 & \multirow{2}{*}{$0.216^{(1)}$} & 10 & 28 & \multirow{2}{*}{$0.062^{(1)}$} \\
\hline & Males & 5 & 76 & & 17 & 61 & & 19 & 59 & & 20 & 59 & & 10 & 70 & \\
\hline \multirow{2}{*}{$\begin{array}{l}\text { Formal } \\
\text { education }\end{array}$} & Yes & 7 & 113 & \multirow{2}{*}{$0.942^{(2)}$} & 21 & 90 & $0813^{(2)}$ & 30 & 85 & $0741^{(2)}$ & 32 & 84 & $0282(2)$ & 20 & 97 & $0831^{(2)}$ \\
\hline & No & 0 & 1 & & 0 & 1 & $0.013^{(2)}$ & 0 & 1 & $0.141^{(2)}$ & 1 & 0 & $0.202^{(1)}$ & 0 & 1 & $0.031^{(2)}$ \\
\hline & $\begin{array}{l}\text { Kinder- } \\
\text { garten }\end{array}$ & 3 & 15 & & 4 & 13 & & 5 & 11 & & 5 & 12 & & 3 & 15 & \\
\hline Schooling & $\begin{array}{c}\text { Elemen- } \\
\text { tary }\end{array}$ & 4 & 95 & & 17 & 74 & & 25 & 71 & & 27 & 69 & & 17 & 79 & \\
\hline $\begin{array}{l}\text { Schooling } \\
\text { level }\end{array}$ & $\begin{array}{l}\text { Unfin. } \\
\text { H.S. }\end{array}$ & 0 & 2 & $0.203^{(1)}$ & 0 & 2 & $0.966^{(1)}$ & 0 & 2 & $0.802^{(1)}$ & 0 & 2 & $0.323^{(1)}$ & 0 & 2 & $0.985^{(1)}$ \\
\hline & $\begin{array}{c}\text { Not } \\
\text { enrolled }\end{array}$ & 0 & 1 & & 0 & 1 & & 0 & 1 & & 1 & 0 & & 0 & 1 & \\
\hline & Yes & 3 & 69 & $0295^{(2)}$ & 10 & 59 & $0113^{(1)}$ & 20 & 48 & $0206^{(1)}$ & 19 & 49 & $0940^{(1)}$ & 11 & 58 & 0729 (1) \\
\hline language & No & 4 & 45 & $0.295^{(2)}$ & 11 & 32 & $0.113^{171}$ & 10 & 38 & $0 . \angle U b^{(1)}$ & 14 & 35 & $0.94 U^{(1)}$ & 9 & 40 & $0.1 \angle y^{111}$ \\
\hline DH written & Yes & 1 & 75 & $0011 *(2)$ & 15 & 54 & 0220 (1) & 19 & 56 & $014^{(1)}$ & 23 & 52 & 0284 (1) & 14 & 61 & $349^{(1)}$ \\
\hline language & No & 6 & 39 & 0.011 & 6 & 37 & $0 . \angle 2 U^{(1)}$ & 11 & 30 & $0.514^{(1 / 1}$ & 10 & 32 & $0.284^{(1)}$ & 6 & 37 & $0.34 y^{111}$ \\
\hline & Yes & 3 & 57 & & 12 & 44 & & 20 & 36 & & 18 & 38 & & 14 & 43 & \\
\hline $\begin{array}{l}\text { cognitive } \\
\text { aspects }\end{array}$ & No & 4 & 57 & $0.509^{(2)}$ & 9 & 47 & $0.315^{(1)}$ & 10 & 50 & $0.019 *(1)$ & 15 & 46 & $0.364^{(1)}$ & 6 & 55 & $0.033^{*(1)}$ \\
\hline $\mathrm{DH}$ sneech & Yes & 2 & 44 & $0461^{(2)}$ & 6 & 36 & $0348^{(1)}$ & 18 & 25 & $0.003 *(1)$ & 19 & 25 & $0.005 *$ (1) & 14 & 31 & $0.020 *(1)$ \\
\hline DH speecr & No & 5 & 70 & $0.401^{121}$ & 15 & 55 & 0.348 & 12 & 61 & 0.003 & 14 & 59 & 0.000 & 6 & 67 & 0.020 \\
\hline & Yes & 0 & 9 & & 1 & 8 & & 1 & 8 & & 0 & 9 & & 0 & 9 & \\
\hline DH fluency & No & 7 & 105 & $0.440^{(2)}$ & 20 & 83 & $0.467^{(2)}$ & 29 & 78 & $0.269^{(2)}$ & 33 & 75 & $0.051^{(2)}$ & 20 & 89 & $0.159^{(2)}$ \\
\hline DH OMF & Yes & 2 & 67 & $0121^{(2)}$ & 13 & 49 & $0.503^{(1)}$ & 18 & 46 & & 21 & 44 & & 12 & 53 & $628^{(1)}$ \\
\hline & No & 5 & 47 & $0.121^{(2)}$ & 8 & 42 & $0.503^{(1)}$ & 12 & 40 & $0.6 / 0^{(1)}$ & 12 & 40 & $0.185^{(1)}$ & 8 & 45 & $0.028^{\prime \prime \prime}$ \\
\hline $\begin{array}{l}\mathrm{DH} \\
\text { Dysphagia }\end{array}$ & No & 7 & 114 & - & 21 & 91 & - & 30 & 86 & - & 33 & 84 & - & 20 & 98 & - \\
\hline & Yes & 1 & 3 & & 2 & 2 & & 1 & 3 & & 1 & 3 & & 1 & 3 & \\
\hline DH audio & No & 6 & 111 & $0.094^{(2)}$ & 19 & 89 & $0.103^{(2)}$ & 29 & 83 & $0.968^{(2)}$ & 32 & 81 & $0.885^{(2)}$ & 19 & 95 & $0.662^{(2)}$ \\
\hline Change in & Yes & 3 & 54 & & 10 & 40 & & 15 & 40 & & 18 & 38 & & 9 & 47 & \\
\hline $\begin{array}{l}\text { the Perc. } \\
\text { Proc. }\end{array}$ & No & 4 & 60 & $0.565^{(2)}$ & 11 & 51 & $0.761^{(1)}$ & 15 & 46 & $0.742^{(1)}$ & 15 & 46 & $0.364^{(1)}$ & 11 & 51 & $0.809^{(1)}$ \\
\hline Change in & Yes & 0 & 28 & & 3 & 21 & & 8 & 18 & & 9 & 17 & & 6 & 20 & \\
\hline $\begin{array}{l}\text { the aud. } \\
\text { proc. }\end{array}$ & No & 7 & 86 & $0.135^{(2)}$ & 18 & 70 & $0.376^{(2)}$ & 22 & 68 & $0.517^{(1)}$ & 24 & 67 & $0.462^{(1)}$ & 14 & 78 & $0.379^{(1)}$ \\
\hline
\end{tabular}

* Significant values $(p<0.05)-{ }^{(1)}=$ Chi-squared test; ${ }^{(2)}=$ Fisher's exact test

Captions: SMNV = Sequential memory test for nonverbal sounds; SMV= Sequential memory test for verbal sounds; DH = Diagnostic Hypothesis; OMF = Orofacial motor functions; Change in the Perc. Proc. = Change in the Perceptual Processes (changes in auditory memory, visual memory, and attention); Changes in the aud. proc. $=$ Changes in the auditory processing; Unfin. H.S. = Unfinished high school. 


\section{DISCUSSION}

The predominance of five- to 12-year-old males in this study also occurred in another study conducted in a teaching clinic related to the Speech-LanguageHearing program at the Universidade Federal do Rio Grande do Sul, Brazil. The results indicated that most referrals were for the screening of speech-languagehearing changes in boys predominantly four to six and eight to 10 years old 9 . Another study, conducted in the department of Speech-Language-Hearing at a public service in the city of Recife, Pernambuco, Brazil, also verified a predominance of males in its sample, as well as a greater need for speech-language-hearing intervention among those zero to 11 years old ${ }^{10}$. A possible explanation for the predominance verified in the number of referrals in the age groups is that it coincided with their entering school - which is when new social relationships begin, the teaching/learning level becomes more demanding, and more attention is given to language issues ${ }^{11}$. The present study corroborates such findings.

The greater prevalence of changes in written and oral language can be explained by the age group to which the patients of this study belonged. At their age, communication demands through written and oral language tend to increase due to the process of increasing socialization and schooling. Hence, existing changes become more evident. This result is similar to that of research conducted at the Hospital das Clínicas de Ribeirão Preto, São Paulo, Brazil, with a sample of 273 medical records of patients five years to 16 years and 11 months old. There was in it a predominance of diagnoses of language delay (27.5\%), language disorder $(20.06 \%)$, and learning disorder $(15.51 \%)^{12}$. In another study, which analyzed the medical records of 524 children aged zero to 11 years, who received care at the Speech-Language-Hearing Clinic of the Universidade de São Paulo, Brazil, the most frequent diagnostic hypotheses were the phonological disorder (22.9\%), changes in the oral myofunctional system $(16.2 \%)$, and changes in oral language $(15.1 \%)^{13}$. As for the analysis of 133 medical records of children up to 12 years old followed up in a speech-languagehearing teaching clinic in the South of Brazil, the most prevalent diagnoses were of change in orofacial motor functions (39.8\%), phonology (20.4\%), language $(11.8 \%)$, and speech $(6.5 \%)^{9}$. All the studies presented similar data, and the literature points out that changes in oral language, including phonological difficulties, can precede impairments in learning to read and write
- which, in turn, will require the involvement of complex cognitive skills ${ }^{14}$. A point that should be highlighted is that the outpatient center where this study took place is an integral part of a reference hospital service in the state, which receives patients with varied clinical diagnoses - some often quite complex or with comorbidities. Therefore, the profile of the cases attended there may tend to a larger number of speech-languagehearing diagnoses when compared to isolated teaching clinic services. Moreover, since it is the specialized component in the health care system, it does not receive cases absorbed and solved in primary health care.

Even though the study has shown a low prevalence of the diagnostic hypothesis of auditory change based on the audiometry and acoustic immittance results, in the cases that did have changes, the conductive characteristic occurred the most. This result is similar to that of research conducted in Alagoas, Brazil, with 190 schoolchildren, which verified a prevalence of hearing loss of $14.2 \%$ in its sample - of which, the most frequent type was conductive, in $13.2 \%$ of the cases, followed by sensorineural loss, present in $7.4 \%^{15}$. The small number of patients with hearing changes in the present study may be due to advancements made in the health policies regarding the diagnosis of hearing loss, although performed unevenly nationwide ${ }^{16}$. Instituting the National Hearing Health Care Policy made it possible to organize a set of comprehensive care measures encompassing all health care levels, aiming at promotion, prevention, treatment, and rehabilitation as well ${ }^{17}$. The high-complexity components within the health system (such as the audiology service in the outpatient center where this study was conducted) are responsible for providing specialized diagnosis and therapy, ensured by the referral and counter-referral process in the network ${ }^{17}$. The presence of a speech-language-hearing therapist at the Extended Family Health and Primary Care Center (NASF-AB, in Portuguese) also has an essential role in the effectiveness of the hearing health policies in primary health care. This professional is responsible for carrying out the actions that aim at health promotion and education, auditory problems earlier identification, and the patients' referrals to the other levels of health care when necessary ${ }^{18}$.

The auditory processing is commonly screened with ASPA $^{8}$, which is sensitive to predict changes in auditory processing. When problems in the skills related to this assessment are verified, it is quite likely 
that behavioral tests, with more complex tasks, will also have changes ${ }^{19}$. ASPA ${ }^{8}$ assesses the temporal ordering (which refers to the capacity to analyze acoustic events through time) and sound localization skills (which depend on the differences in intensity or time of the perceived acoustic stimuli) ${ }^{2}$.

In ASPA, approximately three fourths of the patients in this study had adequate results in the SMNV and SMV tests. Such finding agrees with a previous study conducted with students from a municipal school in Belo Horizonte, Minas Gerais, Brazil, aged eight to 10 years old. In it, $68.2 \%$ of the schoolchildren assessed had adequate results in simple temporal ordering ${ }^{20}$. The sound localization was also found to be adequate in most of those in the sample in the present study. This result is close to the one verified in test and retest carried out with schoolchildren from public schools in the interior of São Paulo State, Brazil, in which none of the participants had changes in the sound localization test ${ }^{4}$. The greater proportion of adequacy in the organization and decoding aspects assessed with ASPA $^{8}$ in the present study was expected, given the fact that the diagnosis of change in the auditory processing was present in less than one fourth of the sample.

Concerning the statistically significant association between the result of the pure-tone threshold audiometry and the diagnostic hypothesis of change in written language, it is possible to infer, agreeing with the literature, that experiencing sounds is part of the school environment, and a change in any auditory skill can trigger difficulties in the process of learning to read and write ${ }^{21}$. The acoustic immittance was not associated with the response variables, a reflex of the adequacy in the outer and middle ear functions in most of those in the sample.

The statistically significant association between the SMNV results and the diagnostic hypotheses of change in speech and cognitive aspects of language, as verified in the present study, can be explained by the fact that the temporal auditory processing encompasses the communication skills - the simple temporal ordering being a requirement for the linguistic skills ${ }^{5}$. Such a result differs from what was verified in a study conducted with seven- to 12-year-old children from inland Minas Gerais whose school performance was poor; it did not reveal an association between the SMNV results and complaints of speech, and oral and written language ${ }^{3}$. This discrepancy may be due to methodological differences between the studies. It should be emphasized that in the present study the analysis of the association was carried out based on diagnostic hypotheses that relied on validated tests, instead of complaints and screenings alone. Another difference is that the patients of the said study were participants of the Specialized Educational Attention (AEE, in Portuguese) due to poor school performance as assessed by their teachers i.e., they were already having some sort of intervention, differently from the patients in this study, who were still undergoing speech-language-hearing assessment to only later start the therapeutic process.

The SMV results also had a statistically significant association with the diagnostic hypothesis of change in speech. This is because temporal ordering is essential to speech and language comprehension; hence, the existence of changes can lead to difficulties related to producing and receiving oral and written messages ${ }^{2,5}$. Previous research conducted in the same setting as the present one, though with a sample of 400 four- to 14-year-old subjects assessed between 2006 and 2010, observed, besides the association between the diagnostic hypothesis of change in speech with the SMV result, that changes are likely to occur in this test in people with a previous complaint of speech ${ }^{5}$. These findings indicate that despite the different periods when the data were collected, the population referred for assessment in the place where the study was conducted maintains a profile of complexity, both in terms of speech-language-hearing diagnoses and the association between them.

Although no statistically significant association was verified in the present study between the auditory assessment variables and the diagnostic hypothesis of oral language, the literature shows that changes in the auditory processing directly interfere with aspects such as phonology ${ }^{22}$ and vocabulary ${ }^{23}$. A previous study was conducted with children aged seven years to nine years and 11 months with a late diagnosis of a phonological disorder. They were divided into a control group (CG), with no changes in the central auditory processing, and a research group (RG), diagnosed with a central auditory processing disorder. The comparison results showed that the RG had on average more types of phonological processes, a larger number of changed results in the assessment tests of rhyme and alliteration metaphonological skills, and more serious phonological disorder rates ${ }^{22}$. An association between auditory processing change and vocabulary changes was also verified in a sample of 96 four- to five-yearold kindergarten students: the children with changed auditory processing were 3.10 times more likely to 
have vocabulary changes ${ }^{23}$. Hence, it is essential to triangulate the auditory and language assessment results (as it was done in this study) to understand the diagnostic process and its protocolizing.

The sound localization test, which assesses aspects of binaural integration ${ }^{2}$, had a statistically significant association with the diagnostic hypotheses of change in the cognitive aspects of language and speech. Such a fact can be explained by the high prevalence of these diagnoses in the sample. Cognition, attention, memory, and language are essential to enable the auditory processing assessment procedures ${ }^{1}$. Therefore, the association of both the sound localization and the SMNV results with the diagnostic hypothesis of change in the cognitive aspects of language can be explained. The association with the diagnostic hypothesis of change in speech occurred because the sound localization skill is essential to develop selective attention, as it helps to separate environmental sounds and analyze the different sound frequencies, intensities, and duration - characteristics important to recognize speech $^{24}$.

The contributions of this study come from its results, which demonstrate the importance of performing ASPA in children with changes in speech and cognitive aspects of language to investigate the changes and hence try to reduce future impacts on communication ad written language, favoring more directed therapeutic interventions. It is further proposed that, during the speech-language-hearing assessment, peripheral and central auditory assessment be systematically performed in school-age children and adolescents. This considers the existing association between the auditory profile and the other speech-language-hearing diagnoses, especially those that refer to changes in speech and language, taking into account the consequences that can be carried into life and development. As for the limitations of the study, there was bias related to filling out the records, as using secondary data caused medical records from the sample to be excluded for lack of information.

\section{CONCLUSION}

The study on the association between auditory assessment and speech-language-hearing diagnosis of children and adolescents that received care at a university outpatient center showed statistically significant associations of hearing loss, SMV, SMNV, and sound localization auditory processing skills with changes in written language, speech, and cognitive aspects of language. Such a fact reveals the importance of performing peripheral, central, and simplified auditory assessment of the auditory processing to identify any changed aspect and carry out complete diagnoses and early intervention - hence, minimizing the impacts on oral communication and written language, as well as favoring more directed therapeutics.

\section{REFERENCES}

1. Carvalho NG, Novelli CVL, Colella-Santos MF. Factors in childhood and adolescence that may influence the auditory processing: a systematic review. Rev. CEFAC. 2015;17(5):1590-603.

2. $[\mathrm{ASHA}]$ American Speech-Language-Hearing Association. (Central) Auditory processing disorders: technical report. [Internet]. Acesso em: 25 de janeiro de 2020. Disponível em: https://www. asha.org/policy/TR2005-00043/.

3. Rezende BA, Lemos SMA, Medeiros AM. Temporal auditory aspects in children with poor school performance and associated factors. CoDAS. 2016;28(3):226-33.

4. Sartori AATK, Delecrode CR, Cardoso ACV. (Central) auditory processing in schoolers in initial literacy grades. CoDAS. 2019;31(1):e20170237 DOI: 10.1590/2317-1782/20182018237

5. Mourão AM, Esteves CC, Labanca L, Lemos SMA. Desempenho de crianças e adolescentes em tarefas envolvendo habilidade auditiva de ordenação temporal simples. Rev. CEFAC. 2012;14(4):659-68.

6. Hage SR de V, Faiad LNV. Perfil de pacientes com alteração de linguagem atendidos na Clínica de Diagnóstico dos Distúrbios da Comunicação Universidade de São Paulo - Campus Bauru. Rev. CEFAC. 2005;7(4):433-40.

7. Peixoto MVS, Siqueira CGA, Silva AF, Pedruzzi CM, Santos AA. Caracterização da população assistida por um serviço de Fonoaudiologia em uma Unidade de Saúde. Distúrb. Comun. 2010;22(2):107-15.

8. Pereira LD. Processamento auditivo central: abordagem passo a passo. In: Pereira LD, Schochat E (orgs). Processamento auditivo central: manual de avaliação. São Paulo: Ed. Lovise; 1997. p.49-59.

9. Cesar LR, Reis RA, Stefani FM. Correlation between speech pathology screening and diagnosis of children aged 0-12 years. Rev. CEFAC. 2016;18(1):129-36. 
10. Barros PML, Oliveira PN. Perfil dos pacientes atendidos no setor de Fonoaudiologia de um serviço público de Recife - PE. Rev. CEFAC. 2010;12(1):128-33.

11. Diniz RD, Bordin R. Demand in Speech-Language Pathology and Audiology in a public service in the South region of Brazil. Rev Soc Bras Fonoaudiol. 2011;16(2):126-31.

12. Mandrá PP, Diniz MV. Characterization of the diagnostic profile and flow of a SpeechLanguage Pathology service in child language within a public hospital. Rev Soc Bras Fonoaudiol. 2011;16(2):121-5.

13. Longo IA, Tupinelli GG, Hermógenes C, Ferreira LV, Molini-Avejonas DR. Prevalence of speech and language disorders in children in the western region of São Paulo. CoDAS 2017;29(6):e20160036 DOI: 10.1590/2317-1782/20172016036

14. Schirmer CR, Fontoura DR, Nunes ML. Language and learning disorders. J. Pediatr. 2004;80(Suppl 2):95-103.

15. Marques LR. A prevalência da perda auditiva detectada por meio da triagem auditiva escolar [dissertação] [Internet]. São Paulo: Universidade Federal de São Paulo - UNIFESP; 2010. Acesso em: 12 de dezembro de 2019 às 17:40h. Disponível em: http://repositorio.unifesp.br/handle/11600/8840.

16. Andrade CL, Fernandes L, Ramos HE, Mendes CMC, Alves CAD. National Program For Hearing Health Care: advances and obstacles of hearing health in Brazil. Rev. Ciênc. Méd. Biol. 2013;12(especial):404-10.

17. Brasil. Ministério da Saúde. Portaria no 2.073, de 28 de setembro de 2004. Institui a Política Nacional de Atenção à Saúde Auditiva [Internet]. Brasília, 2004. Acesso em: 22 de julho de 2019. Disponível em: http://bvsms.saude.gov.br/bvs/saudelegis/ gm/2004/prt2073_28_09_2004.html.

18. Conselho Federal de Fonoaudiologia. Guia de orientação para implantação e desenvolvimento da saúde auditiva na Atenção Primária. Brasília, 2011. [Internet]. Acesso em: 27 de setembro de 2019 às 21:35h. Disponível em: https://www.fonoaudiologia. org.br/publicacoes/cartilha_fonoaudiologos_ alterada.pdf.

19. Vargas GC, Ferreira MIDC, Vidor DCGM, Machado MS. Auditory processing screening and behavioral evaluation in students: establishing relations. Rev. CEFAC. 2014;16(4):1069-77.
20. Souza CA, Escarce AG, Lemos SMA. Temporal ordering and reading competence of words and pseudowords: a preliminary study. CoDAS. 2018;30(2):e20170102 DOI: 10.1590/2317-1782/20182017102

21. Torquato RJ. A alteração do processamento auditivo e a relação com a dificuldade de aprendizagem na escrita [monografia] [Internet]. Curitiba: Universidade Tuiuti do Paraná; 2012. Acesso em: 25 de agosto de 2019. Disponível em: https:// tcconline.utp.br/wp-content/uploads//2012/08/AALTERACAO-DO-PROCESSAMENTO-AUDITIVOE-A-RELACAO-COM-A-DIFICULDADE-DEAPRENDIZAGEM-DA-ESCRITA.pdf.

22. Barrozo TF, Pagan-Neves LO, Vilela N, Carvallo RMM, Wertzner HF. The influence of (central) auditory processing disorder in speech sound disorders. Braz $\mathrm{J}$ Otorhinolaryngol. 2016;82(1):56-64.

23. Souza MA, Passaglio NJS, Souza VC, Scopel RR, Lemos SMA. Temporal ordering and sound localization: association with environment and language development. Audiol. Commun. Res. 2015;20(1):24-31.

24. Dias TLL, Pereira LD. Sound localization and lateralization in individuals with visual deficiency. Rev Soc Bras Fonoaudiol. 2008;13(4):352-6. 